\title{
The physician-scientist: defending vaccines and combating antiscience
}

\author{
Peter Hotez \\ Texas Children's Hospital Center for Vaccine Development, Departments of Pediatrics and Molecular Virology \& Microbiology, National School of Tropical Medicine; and Center for Medical Ethics and Health \\ Policy, Baylor College of Medicine, Houston, Texas, USA.
}

$T_{1}$ 2019 measles outbreaks across America may signal a new phase in the antivaccine movement. For the first time, antivaccine sentiments have mainstreamed to adversely and widely affect child health in the United States.

With many parents convinced that vaccines are dangerous, there are now more than 100 pockets of very low vaccine coverage in at least a dozen US states (1). Because of its high transmissibility, the measles virus is often the first to cause breakthrough childhood infections in such areas of vaccine refusal, especially among infants not old enough to receive their first vaccine dose (2). According to the CDC, 555 measles cases have been confirmed in 20 states in the first quarter of 2019 (3), with the largest outbreaks so far occurring in Washington and Oregon (78 cases) and Texas (14 cases). In New York, more than 400 measles cases have been reported since the end of 2018. These outbreaks are likely just the beginning: the CDC reports that at least 100,000 children in the United States are fully unvaccinated (4), while in Texas alone 76,000 parents requested "conscientious exemption affidavits" for their children in 2018, more than a 60 percent increase since 2014 and almost a 20 percent increase since the previous year (5).

We find ourselves in a deplorable situation in which infants and children are routinely and deliberately denied access to many of their vaccines, including measles-mumps-rubella (MMR) vaccinations, despite the strong recommendations to vaccinate from the CDC, its Advisory Committee on Immunization Practices
(ACIP), and all of the major pediatric and academic societies. Things appear to be even worse in Europe: the European CDC reports almost 900 measles cases in the month of January, with the largest numbers in Romania, Italy, Poland, and France (6).

How did we get to this point?

\section{Antivax on the rise}

Ever since inoculation with smallpox (a practice known as variolation) was practiced in Colonial America, the safety of vaccines and the role of vaccine mandates have been questioned (7) Beginning in the 1950s and '60s with the introduction of both the Salk and Sabin polio vaccines, followed by vaccines for measles and other serious childhood infections, we entered a golden age when vaccines were almost universally acclaimed as miracle or lifesaving technologies. Through a vaccination campaign, smallpox became the first human disease ever eradicated, followed by dramatic reductions in the numbers of deaths from measles, pertussis, and tetanus resulting from the global vaccination programs that followed - the Expanded Program on Immunization (EPI) led by the World Health Organization (WHO) in 1974 and later Gavi, The Vaccine Alliance, in 2000 (7).

Shortly before Gavi was created, the modern-day version of today's antivaccine movement began in response to a 1998 article in the Lancet alleging that the MMR vaccine causes pervasive developmental disorder, now known as autism. Even though the paper was subsequently retracted by the Lancet editors, during
Conflict of interest: PH holds patents on vaccines for several poverty-related neglected diseases and neglected tropical diseases, including hookworm infection, schistosomiasis, and Chagas disease $(5,527,937 ; 5,753,787$ 7,303,752 B2; 12/492,734; 61/077,256; PCT-20100701/0.20.5.18; PCT-61448231). None of these patents have generated revenue. PH is the author of the book Vaccines Did Not Cause Rachel's Autism: My Journey as a Vaccine Scientist, Pediatrician, and Autism Dad.

Copyright: (c) 2019, American Society for Clinical Investigation.

Reference information: J Clin Invest. 2019;129(6):2169-2171. https://doi.org/10.1172/JCI129121. the decade of the 2000s, antivaccine sentiments amplified on the internet and established in new e-commerce and social media platforms.

Today, the antivaccine (sometimes referred to as "antivax" or "antivaxxer") movement has evolved into its own media empire (Figure 1). One report indicates that there are now at least 480 antivaccine websites on the internet (8), which are amplified routinely on social media sites, especially Facebook and Twitter. Amazon is now the largest purveyor of antivax books, such that many of the top-selling books on vaccination are against vaccines. Not surprisingly, antivaccine misinformation is now pervasive to the point where it is difficult for parents to easily download accurate health information about vaccines.

The movement has also added a political dimension. Many states now host their own antivax political action committees (PACs) lobbying to enact legislation to make it easier for parents to exempt their children from mandatory school vaccines or to make it more difficult for schools to require vaccinations. Both the media and political elements of the antivaccine lobby have recently accelerated to a point where we can anticipate future measles outbreaks and declines in vaccinations against many other childhood infections, including influenza.

\section{Ignoring the science: vaccines and autism}

The antivaccine movement does not always speak with a single voice, and its rationale for objecting to vaccines or questioning their safety can vary. However, the most common reason cited by major antivax websites, social media sites, books sold through Amazon, and even a major documentary, is that vaccines cause childhood autism (7). In many cases the MMR vaccine is cited as the offending vaccine, but more recently it has been alleged that autism results from the thimerosal preser- 


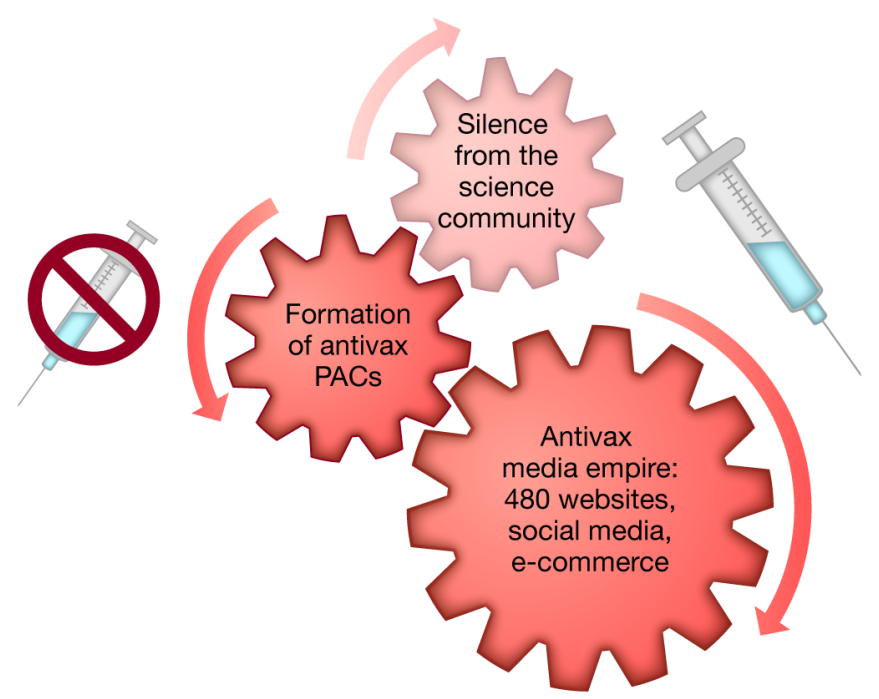

Figure 1. The three major drivers of the antivax movement. Since the early 2000 s, the antivax movement has grown into its own "media empire" with a political arm. The response from the scientific community and federal government agencies committed to public health has been modest or tepid. Figure illustrated by Rachel Davidowitz.

vative that was previously in many childhood vaccines or from aluminum-containing adjuvants, or that somehow an infant's fragile immune system is overwhelmed by administration of too many vaccines simultaneously.

As both a pediatrician-scientist who develops vaccines to prevent neglected tropical diseases (NTDs) and a parent of an adult daughter with autism, I spent months investigating possible vaccine-autism links, only to find massive evidence involving over one million children confirming no link between any vaccine and autism (7). The studies show that children who are vaccinated are no more likely to be on the autism spectrum than unvaccinated children, while children with an autism diagnosis are no more likely to have gotten vaccinated than children not on the autism spectrum (7). More recently, a nationwide cohort study following more than 650,000 children in Denmark and published in 2019 confirmed there is no increased risk for autism following the MMR vaccination, including in children with autism risk factors as defined by their sibling history of autism (9).

I also point out how my daughter Rachel's autism was not caused by vaccines, and there is no real plausibility of linking the two (7). Over the last two decades, we have learned a lot about autism and how it begins in early fetal development $(10,11)$. In 2018, a large international collaboration led by the Broad Institute at Harvard-MIT found that autism genes are expressed early on in brain development (mostly in the neocortex) and are linked to neuronal communication or gene expression (11). They include genes encoding the neuronal cytoskeleton - through wholeexome sequencing done at Baylor Genetics, we think a similar gene may possibly be involved in Rachel's autism.

We have also learned a lot about the clinical expression of autism and how it often fully manifests in the second or third year of life. Studies at the University of North Carolina at Chapel Hill and elsewhere elucidate how an autism diagnosis might coincide with an increase in brain volume expansion, which can be seen on MRI, but these changes actually begin as hyperexpanding cortical areas as early as six months of age (12). That is an important finding for parents, because many will claim their child's autism began around 18 months of age or later following a vaccination in the second year of life. Indeed, Rachel's condition also first came to medical attention around that time (7). But we can now say with some confidence that the developmental program leading to autism begins in pregnancy, with changes on MRI apparent beginning at 6 months of age (7). Such findings do not preclude the possible role of environmental and epigenetic effects during fetal development
(13), including the finding of at least a halfdozen chemical exposures during pregnancy that have been linked to autism (14).

\section{Physician-scientists as 21st- century science defenders and health advocates}

Synthesizing the information that de-links vaccines from autism requires a strong scientific background, while conveying this message requires the interest and willingness to take the time to engage in public discussions. Unfortunately, health communication and messaging are still often neglected in most physicianscientist training programs. Indeed in my $\mathrm{MD} / \mathrm{PhD}$ training during the 1980 s, we received a strong message that speaking with journalists or engaging in public discourse was not looked upon favorably and was even criticized or condemned $(7,15)$. However, times have changed, and now the antivax and other antiscience movements have conquered the Internet and disseminate misinformation on a scale that far exceeds the accurate messaging from scientists. We therefore must look to new roles for at least some physicianscientists in taking on high-profile public engagement activities. As of 2019, science is losing the battle to antiscience, and now children are increasingly denied the fundamental right of access to vaccines. Yet as Research!America points out, the vast majority of Americans cannot name a living scientist (15), and those who can seldom identify one that still does what most of us do on a daily basis - revise papers, struggle over NIH grant applications, and wring our hands at weekly lab meetings. Essentially, the American public has absolutely no idea about what we do or the fundamentals of scientific inquiry. This disconnect creates suspicion, sometimes leading to unfounded conspiracy theories.

Ultimately, we must recognize how speaking out and reversing this tide is a necessary and vital element of physicianscientist training and professional activities. If we don't do it, no one else is likely to step up and assume this mantle.

\section{Acknowledgments}

The author would like to thank his wife, Ann, and family, especially Rachel Hotez, for their enthusiastic support in defending vaccines in America. 
Address correspondence to: Peter Hotez, One Baylor Plaza, Suite 164a, Houston, Texas 77030, USA. Phone: 713.798.3355; Email: hotez@bcm.edu.

1. Olive JK, Hotez PJ, Damania A, Nolan MS. The state of the antivaccine movement in the United States: a focused examination of nonmedical exemptions in states and counties. PLoS Med. 2018;15(6):e1002578.

2. Hotez PJ. Texas and its measles epidemics. PLoS Med. 2016;13(10):e1002153.

3. Measles cases in 2019. Centers for Disease Control and Prevention Web Site. https://www.cdc. gov/measles/cases-outbreaks.html. Updated April 11, 2019. Accessed April 19, 2019.

4. Hill HA, Elam-Evans LD, Yankey D, Singleton JA, Kang Y. Vaccination coverage among children aged 19-35 months - United States, 2017. MMWR Morb Mortal Wkly Rep. 2018;67(40):1123-1128.

5. Downs C. 45,000 Texan students requested conscientious exemptions from vaccinations in
2018. San Antonio Express-News. March 16, 2019. https://www.mysanantonio.com/news/ education/article/76-000-Texan-studentsrequested-conscientious-13685867.php. Accessed April 12, 2019.

6. Monthly measles and rubella monitoring report, March 2019. European Centre for Disease Prevention and Control Web Site. https://www. ecdc.europa.eu/en/publications-data/monthlymeasles-and-rubella-monitoringreport-march-2019. Published March 8, 2019. Accessed April 12, 2019.

7. Hotez PJ. Vaccines Did Not Cause Rachel's Autism: My Journey as a Vaccine Scientist, Pediatrician, and Autism Dad. Baltimore, Maryland, USA: Johns Hopkins University Press; 2018.

8. Moran MB, Lucas M, Everhart K, Morgan A, Prickett E. What makes anti-vaccine websites persuasive? A content analysis of techniques used by antivaccine websites to engender anti-vaccine sentiment. JComm Healthcare. 2016;9(3):151-163.

9. Hviid A, Hansen JV, Frisch M, Melbye M. Measles, mumps, rubella vaccination and autism: a nationwide cohort study. Ann Intern Med. 2019;170(8):513-520.

10. Stoner R, et al. Patches of disorganization in the neocortex of children with autism. N Engl JMed. 2014;370(13):1209-1219.

11. Satterstrom F, et al. Novel genes for autism implicate both excitatory and inhibitory cell lineages at risk [preprint]. doi: https://doi. org/10.1101/484113. Posted on BioRxiv. November 30, 2018. Accessed April 12, 2019.

12. Piven J, Elison JT, Zylka MJ. Toward a conceptual framework for early brain and behavior development in autism. Mol Psychiatry. 2017;22(10):1385-1394.

13. Forsberg SL, Ilieva M, Maria Michel T. Epigenetics and cerebral organoids: promising directions in autism spectrum disorders. Transl Psychiatry. 2018;8(1):14.

14. Landrigan PJ. What causes autism? Exploring the environmental contribution. Curr Opin Pediatr. 2010;22(2):219-225.

15. Hotez PJ. Crafting your scientist brand. PLoS Biol. 2018;16(10):e3000024. 